\title{
Factors Associated with Blood Pressure Checkup During Pregnancy Among Women of Reproductive Age in Tanzania; An Analysis of Data from the 2015- 16 Tanzania Demographic and Health Survey and Malaria Indicators Survey
}

Fabiola Vincent Moshi ( $\square$ fabiola.moshi@gmail.com )

The University of Dodoma College of Health Sciences https://orcid.org/0000-0001-8829-2746

Maximilian Tungaraza

The University of Dodoma College of Health Sciences

Research article

Keywords: Blood pressure, checkups, pregnant women

Posted Date: July 21st, 2020

DOI: https://doi.org/10.21203/rs.3.rs-44299/v1

License: (c) (1) This work is licensed under a Creative Commons Attribution 4.0 International License.

Read Full License 


\section{Abstract}

Background: Hypertensive Disorder of Pregnancy (HDP) is one of the leading causes of maternal mortality and morbidity amongst pregnant women in the world. Blood pressure checkups during pregnancy are on of strategies to identify hypertensive disorders and hence timely management. Little is known on factors associated with blood pressure checkups in Tanzania.

Method: The study used data from the 2015-16 Tanzania Demographic and Health Survey and Malaria Indicators Survey (2015-16 TDHS-MIS). A total of 6924women of active reproductive age from 15 to 49 were included in the analysis. Both univariate and multiple regression analyses were used to determine the association between early antenatal booking and maternal services utilization.

Results: A total of 4997(72.17\%) of interviewed women were checked for blood pressure at least once. After adjusted for the confounders, factors which influenced uptake of blood pressure checkups during pregnancy were timing for antenatal booking within first 12 weeks, $A O R=1.496$ at $95 \% \mathrm{Cl}=1.297$ $1.726, p<0.001$, age group [ more than 34 years, $(A O R=1.518$ at $95 \% \mathrm{Cl}=1.149-2.006, p=0.003)$ ], wealth index [ middle income, $(\mathrm{AOR}=1.215$ at $95 \% \mathrm{Cl}=1.053-1.468, \mathrm{p}=0.008)$ and rich, $(\mathrm{AOR}=2.270$ at $95 \%$ $\mathrm{Cl}=1.907-2.702, \mathrm{p}<0.001)$ ] reference population being poor; education level [ primary education, $(A O R=1.275$ at $95 \% \mathrm{Cl}=1.107-1.468, p=0.001)$; secondary, $(A O R=2.163$ at $95 \% \mathrm{Cl}=1.688-2.774, p<0.001)$ and higher, $(A O R=9.929$ at $95 \% \mathrm{Cl}=1.355-72.76, p=0.024)]$ reference population being no formal education; parity[para 2-4, $(\mathrm{AOR}=1.190$ at $95 \% \mathrm{Cl}=1.003-1.412, \mathrm{p}=0.046)$ and zones [Unguja Island, $(\mathrm{AOR}=3.934$ at $95 \% \mathrm{Cl}=1.568-9.871, \mathrm{p}=0.004)$ and Pemba Island, $(\mathrm{AOR}=5.308$ at $95 \% \mathrm{Cl}=1.808-15.58$, $\mathrm{p}=0.002)$ ] Mainland urban being the reference population

Conclusion: Blood pressure checkups during pregnancy offer the opportunity for early detection timely management of HDP. The study revealed that rural dwelling pregnant women had higher chance not to get their BP checked. It was also revealed that maternal age, education level, place of residence, wealth index and timing of ANC services significantly associated with blood pressure check-ups. The study identifies the need to explore significant factors associated with utilization of the available free reproductive health services across all public health facilities and to address prioritized intensive awareness programs and behavioral change interventions on the significance of BP checkups among pregnant women of reproductive age.

\section{Background}

Maternal mortality is inadmissibly high worldwide. In 2017, about 295000 women died during pregnancy and childbirth. About $94 \%$ of these deaths occurred in low-resource settings, and most could have been prevented [1]. Sub-Saharan countries are reported to have 533 maternal deaths per 100,000 live births, which is equal to 200,000 maternal deaths yearly. The SSA alone accounts for the two thirds of all global maternal deaths per year [2]. In Tanzania, about 556 maternal deaths per 100,000 live births occurred [3]. Maternal deaths occur due to both direct and indirect causes. Direct causes of maternal deaths include 
postpartum haemorrhage, hypertensive disorders, puerperal sepsis, unsafe abortion and obstructed labour [4].

Globally, hypertensive disorder of pregnancy (HDP) is one of the leading direct causes of maternal mortality and morbidity amongst pregnant women [5, 6]; accounting for nearly $12 \%$ of the global maternal deaths [5]. Hypertension in pregnancy is a condition in which systolic blood pressure (SBP) measures $\geq 140 \mathrm{mmHg}$ and/or diastolic blood pressure (DBP) of $\geq 90 \mathrm{mmHg}$ confirmed when blood pressure is measured within four hours apart. HDP encompasses a variety of disorders which include preexisting hypertension, gestational hypertension, preeclampsia/eclampsia, and superimposed hypertension [6]. Pre-eclampsia and eclampsia cause the most serious consequences to the mother and the baby [7]. These conditions are associated with vasospasm, pathologic vascular lesions in multiple organ systems, increased platelet activation and resulting in derangement of coagulation system in the small blood vasculature [7]. A study done in Turkey found that hypertensive disorders was the third most frequent cause among all causes and the second among direct causes of maternal deaths [8].

Tanzania ranked the 4th highest number of maternal deaths in Sub-Saharan Africa and the 6th highest in the world [9]. Hypertensive disorders, especially eclampsia contributed about $19 \%$ of maternal deaths, and it was reported the 2nd after postpartum hemorrhage, in Tanzania [10] (Ministry of Health, Community Development, Gender, Elderly and Children, 2018). The incidence of preeclampsia was estimated to be seven times higher in developing countries than developed countries ranging from 1.8$16.7 \%[7]$.

Blood pressure (BP) checkups during pregnancy are one of strategies to identify hypertensive disorders and hence timely management [11]. However, the check-ups depend on adequate and timely antenatal care (ANC) services utilization. ANC attendance offers the mother with opportunity to undergo blood pressure check-ups $[12,13]$. Studies have shown that majority of women in sub-Saharan Africa book ANC services late [12-14]. Recent WHO guideline recommends the pregnant woman to undergo blood pressure checkups for not less than eight times, where the first takes place in the first trimester, 2 checkups in the second trimester, and 5 checkups in the third trimester [15]. Late ANC initiations deny pregnant women from meeting this goal; hence becoming difficult detecting and managing HDP timely [16]. According to TDHS 2015/16, about $49 \%$ of pregnant women did not complete the recommended ANC contacts, hence likely to miss the opportunity to check their blood pressure [17].

Potential associated factors were extracted from the literature which included maternal age, place of residence, education level, socioeconomic status, parity and timing of ANC services. Maternal age have been reported in some studies $[18,19]$. Moreover, two studies done in Ethiopia found that place of residence and education level of the woman contributed to status of ANC attendance for BP checkups $[20,21]$. Educated woman have a greater awareness of the existence of ANC services and the benefits of using such services [22]. Furthermore, socioeconomic status of the woman was also a challenge. Studies showed that good economic status of the woman enables her complete the required number of required BP check-ups $[19,22,23]$. Moreover, a systematic review study that included 74 studies found that low 
parity was associated with adequate ANC service utilization [23]. Women with high parity tend to underutilize ANC services, hence, missing the opportunity to have their blood pressure adequately checked [24, 25].

However, little is known on factors associated with blood pressure checkups in Tanzania. The study thus set out to analyze factors associated with blood pressure checkups during pregnancy among women of reproductive age in Tanzania, using data from the 2015-16 Tanzania HIV and Malaria Indicators Survey.

\section{Methods}

\section{Study Area and period}

The study was conducted in the United Republic of Tanzania from August 22, 2015, through February 14, 2016.Tanzania among the countries found in East Africa. It is the largest country that covers 940,000 square kilometers and 60,000 square kilometers is inland water. The country lies south of the equator and shares borders with eight countries: Kenya and Uganda to the North; Rwanda, Burundi, the Democratic Republic of Congo, and Zambia to the West; and Malawi and Mozambique to the South.

\section{Study Design}

It was a national-based cross-sectional study utilizing the 2015-16 Tanzania Demographic and Health Survey and Malaria Indicator Survey (TDHS-MIS) dataset.

\section{Study Population}

All women of reproductive age (aged 15-49 years) were the study population. The study used Individual file recode (TZIR7BFL) with a total of 13266 women who responded to the survey ( $97 \%$ response rate). The study included only women who remembered the timing for antenatal booking of their youngest child. Those who were not able to recall the timing and those who did not respond to the question were removed from the analysis. A total of 6924 women who had birth within five years preceding the survey were included in the study.

\section{Sampling Technique}

Two stages of sampling were used to obtain a sample for urban and rural areas in Tanzania Mainland and Zanzibar. In the first stage, a total of 608 clusters were selected and in the second stage, a systematic selection of households was involved. A total of 22 households were then systematically selected from each cluster, yielding a representative probability sample of 13,376 households for the 2015-16 TDHS-MIS. To enhance representativeness Tanzania was divided into nine geographic zones. Grouping the regions into zones was done to reduce sampling error by increasing the number of people in 
the denominator. The zone was western (Tabora and Kigoma regions), Northern zone (Kilimanjaro, Tanga, and Arusha), Central zone (Dodoma, Singida and Manyara), Southern Highland zone (Iringa, Njombe, and Iringa), Southern zone (Lindi and Mtwara), South West Highland zone (Mbeya Rukwa and Katavi), Lake zone (Kagera, Mwanza, Geita, Mara, Simiyu, and Shinyanga), Eastern zone (Dar es Salaam, Pwani, and Morogoro) and Zanzibar (Kaskazini Unguja, Kusini Unguja, Mjini Magharibi, Kaskazini Pemba and Kusini Pemba).

\section{Data Collection Tool}

The 2015-16 TDHS-MIS used household questionnaires and individual questionnaires. These questionnaires based on the Measure DHS standard AIDS Indicator Survey and Malaria Indicator Survey questionnaires standards. They were adapted and modified to reflect the Tanzanian population. They were translated into Kiswahili, Tanzania's national language. The data presented in this study are from the individual questionnaire.

\section{Study variables}

1. Dependent Variable: Blood pressure check-up

2. Independent Variables: Maternal Age, Place of Residence, Marital Status, Socioeconomic status (Wealth Index) and parity of the mother.

\section{Data analysis}

Data were analyzed using Statistical Package for Social Sciences (IBM SPSS version 20). Data analysis started by describing all study variables using frequencies and percentages, we then assessed the association between a dependent variable and independent variables using the chi-squared test, and finally, we performed binary logistic regression analysis (univariate and multivariable) to determine significant predictors for uptake of blood pressure checkup during pregnancy.

\section{Results}

Majority of study respondents $5113(73.8 \%)$ resided in the rural setting of Tanzania, aged 20 to 34 years 4557(65.8\%), had primary education 4209(60.8) and were married 5650(86.1\%) Table 1 
Table 1

Socio-demographic Characteristics

\begin{tabular}{|c|c|c|}
\hline Variables & Frequency & Percent (\%) \\
\hline \multicolumn{3}{|l|}{ Place of residence } \\
\hline Urban & 1811 & 26.2 \\
\hline Rural & 5113 & 73.8 \\
\hline \multicolumn{3}{|l|}{ Age group } \\
\hline Less than 20 years & 541 & 7.8 \\
\hline 20 to 34 years & 4557 & 65.8 \\
\hline More than 34 years & 1826 & 26.4 \\
\hline \multicolumn{3}{|l|}{ Educational level } \\
\hline No education & 1329 & 19.2 \\
\hline Primary education & 4209 & 60.8 \\
\hline Secondary & 1326 & 19.2 \\
\hline Higher & 60 & 0.9 \\
\hline \multicolumn{3}{|l|}{ Parity } \\
\hline Para one & 1595 & 23 \\
\hline Para 2-4 & 3154 & 45.6 \\
\hline Para 5+ & 2175 & 31.4 \\
\hline \multicolumn{3}{|l|}{ Wealth index } \\
\hline Poor & 2734 & 39.5 \\
\hline Middle & 1363 & 19.7 \\
\hline Rich & 2827 & 40.8 \\
\hline \multicolumn{3}{|l|}{ Marital Status } \\
\hline Never in union & 441 & 6.4 \\
\hline Married & 5650 & 86.1 \\
\hline Widow & 119 & 1.7 \\
\hline Separated & 714 & 10.3 \\
\hline \multicolumn{3}{|c|}{ Respondent currently working } \\
\hline Not working & 1498 & 21.6 \\
\hline
\end{tabular}




\begin{tabular}{|lll|}
\hline Variables & Frequency & Percent (\%) \\
\hline Working & 5426 & 78.4 \\
\hline Mainland/Zanzibar & & \\
Mainland urban & 1618 & 23.4 \\
Mainland rural & 4357 & 62.9 \\
Unguja (Zanzibar Island) & 594 & 8.6 \\
\hline Pemba (Pemba Island) & 355 & 5.1 \\
\hline
\end{tabular}

INSERT Table 1 HERE

\section{Ever Checked Blood Pressure During Pregnancy}

Majority of interviewed women, 4997 (72.2\%) were checked for their blood pressure at least once while a total of 1927(27.8) were never checked for their blood pressure during pregnancy (Fig. 1)

INSERT FIGURE 1 HERE

The relationship between women's characteristics and ever checked blood pressure during pregnancy

Women's characteristics which showed significant relationship with ever checked for blood pressure were place of residence $(p<0.001)$, age group $(p<0.001)$, education level $(p<0.001)$, parity $(p<0.001)$, wealth index $(p<0.001)$ and zones $(p<0.001)$ Table 2. 
Table 2

The Relationship between women's characteristics and ever checked blood pressure during pregnancy

\begin{tabular}{|c|c|c|c|c|}
\hline Variables & Ever Checked & Never Checked & $X 2$ & p-value \\
\hline & $\mathrm{n}(\%)$ & $\mathrm{n}(\%)$ & & \\
\hline \multicolumn{5}{|l|}{ Place of residence } \\
\hline Urban & 1593(88) & $218(12)$ & & \\
\hline Rural & $3404(66.6)$ & 1709(33.4) & 304.553 & $<0.001$ \\
\hline \multicolumn{5}{|l|}{ Age group } \\
\hline $15-19$ & $340(62.8)$ & 201(37.2) & & \\
\hline $20-34$ & $3319(72.8)$ & 1238(27.20) & & \\
\hline $35-49$ & 1338(73.3) & 488(26.7) & 25.521 & $<0.001$ \\
\hline \multicolumn{5}{|l|}{ Educational level } \\
\hline No education & $823(61.9)$ & $506(38.1)$ & & \\
\hline Primary education & 2922(69.4) & $1287(30.6)$ & & \\
\hline Secondary & 1193(90.0) & 133(10) & & \\
\hline Higher & $59(98.3)$ & $1(1.7)$ & 314.868 & $<0.001$ \\
\hline \multicolumn{5}{|l|}{ Parity } \\
\hline Para one & $1165(73)$ & $430(27)$ & & \\
\hline Para 2-4 & 2362(74.9) & $792(25.1)$ & & \\
\hline Para 5+ & $1470(67.6)$ & $705(32.4)$ & 34.964 & $<0.001$ \\
\hline \multicolumn{5}{|l|}{ ANC Booking } \\
\hline Late booking & $3746(70.2)$ & 1592(29.8) & & \\
\hline Early booking & 1251(78.9) & $335(21.1)$ & 46.094 & $<0.001$ \\
\hline \multicolumn{5}{|l|}{ Wealth index } \\
\hline Poor & 1586(58) & $1148(42)$ & & \\
\hline Middle & $923(67.7)$ & $440(32.3)$ & & \\
\hline Rich & 2488(88) & $339(12)$ & 639.450 & $<0.001$ \\
\hline \multicolumn{5}{|l|}{ Marital Status } \\
\hline Never in union & $325(73.7)$ & 116(26.3) & & \\
\hline
\end{tabular}




\begin{tabular}{|lllll|}
\hline Variables & Ever Checked & Never Checked & X2 & p-value \\
\hline Married & $4075(72.1)$ & $1575(27.9)$ & & \\
\hline Widow & $88(73.9)$ & $31(26.1)$ & & \\
\hline Separated & $509(71.3)$ & $205(28.7)$ & 0.981 & 0.806 \\
\hline Mainland/Zanzibar & & & & \\
\hline Mainland urban & $1405(86.8)$ & $213(13.2)$ & & \\
\hline Mainland rural & $2676(61.4)$ & $1681(38.6)$ & & \\
\hline Unguja (Zanzibar Island) & $575(96.8)$ & $19(3.2)$ & & \\
\hline Pemba (Pemba Island) & $341(96.1)$ & $14(3.9)$ & 704.290 & $<0.001$ \\
\hline
\end{tabular}

INSERT Table 2 HERE

After adjusted for the confounders, factors which influenced uptake of blood pressure checkups during pregnancy were timing for antenatal booking within first 12 weeks, $A O R=1.496$ at $95 \% \mathrm{Cl}=1.297-1.726$, $p<0.001$, age group [more than 34 years, $(A O R=1.518$ at $95 \% \mathrm{Cl}=1.149-2.006, p=0.003)$ ], wealth index [ middle income, $(A O R=1.215$ at $95 \% \mathrm{Cl}=1.053-1.468, p=0.008)$ and rich, $(A O R=2.270$ at $95 \% \mathrm{Cl}=$ $1.907-2.702, p<0.001)$ ] reference population being poor; education level [ primary education, $(A O R=$ 1.275 at $95 \% \mathrm{Cl}=1.107-1.468, \mathrm{p}=0.001)$; secondary, $(\mathrm{AOR}=2.163$ at $95 \% \mathrm{Cl}=1.688-2.774, \mathrm{p}<0.001)$ and higher, $(A O R=9.929$ at $95 \% \mathrm{Cl}=1.355-72.76, p=0.024)]$ reference population being no formal education; parity[para $2-4,(\mathrm{AOR}=1.190$ at $95 \% \mathrm{Cl}=1.003-1.412, \mathrm{p}=0.046)$ and zones [Unguja Island, $(A O R=3.934$ at $95 \% \mathrm{Cl}=1.568-9.871, p=0.004)$ and Pemba Island, $(A O R=5.308$ at $95 \% \mathrm{Cl}=1.808-$ $15.58, p=0.002$ )] Mainland urban being the reference population (Table 3 ). 
Table 3

Factors associated with ever checked blood pressure during pregnancy

\begin{tabular}{|c|c|c|c|c|c|c|c|c|}
\hline \multirow[t]{2}{*}{ Variable } & \multirow[t]{2}{*}{ OR } & \multicolumn{2}{|l|}{$95 \% \mathrm{Cl}$} & \multirow{2}{*}{$\begin{array}{l}\text { p- } \\
\text { value }\end{array}$} & \multirow[t]{2}{*}{ AOR } & \multicolumn{3}{|l|}{$95 \% \mathrm{Cl}$} \\
\hline & & Lower & Upper & & & Lower & Upper & $\begin{array}{l}\text { p- } \\
\text { value }\end{array}$ \\
\hline \multicolumn{9}{|l|}{ ANC Booking } \\
\hline Late booking & 1 & & & & 1 & & & \\
\hline Early booking & 1.587 & 1.388 & 1.815 & $<.001$ & 1.496 & 1.297 & 1.726 & $\begin{array}{l}<.001 \\
0.001\end{array}$ \\
\hline
\end{tabular}

\section{Age groups}

Less than 20 years $\quad 1$

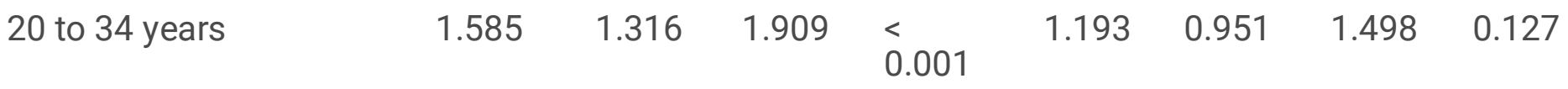

$\begin{array}{lllllllll}\text { More than } 34 \text { years } & 1.621 & 1.323 & 1.985 & < & 1.518 & 1.149 & 2.006 & 0.003\end{array}$

\section{Place of residence}

$\begin{array}{lllllllll}\text { Urban } & 1 & & & & & & & \\ \text { Rural } & 0.273 & 0.234 & 0.318 & < & 1.044 & 0.388 & 2.81 & 0.932\end{array}$

\section{Wealth index}

\begin{tabular}{|c|c|c|c|c|c|c|c|c|}
\hline Poor & 1 & & & & 1 & & & \\
\hline Middle & 1.518 & 1.325 & 1.741 & $\begin{array}{l}< \\
0.001\end{array}$ & 1.215 & 1.053 & 1.402 & 0.008 \\
\hline Rich & 5.312 & 4.634 & 6.09 & $\begin{array}{l}< \\
0.001\end{array}$ & 2.27 & 1.907 & 2.702 & $\begin{array}{l}< \\
0.001\end{array}$ \\
\hline
\end{tabular}

Educational level

\begin{tabular}{|c|c|c|c|c|c|c|c|c|}
\hline No education & 1 & & & & 1 & & & \\
\hline Primary education & 1.396 & 1.227 & 1.588 & $<.001$ & 1.275 & 1.107 & 1.468 & 0.001 \\
\hline Secondary & 5.515 & 4.468 & 6.808 & $<.001$ & 2.163 & 1.688 & 2.774 & $\begin{array}{l}< \\
0.001\end{array}$ \\
\hline Higher & 36.275 & 5.01 & 262.6 & $<.001$ & 9.929 & 1.355 & 72.76 & 0.024 \\
\hline \multicolumn{9}{|l|}{ Parity } \\
\hline List of figures & & & & & & & & \\
\hline
\end{tabular}




\begin{tabular}{|c|c|c|c|c|c|c|c|c|}
\hline \multirow[t]{2}{*}{ Variable } & \multirow[t]{2}{*}{ OR } & \multicolumn{2}{|l|}{$95 \% \mathrm{Cl}$} & \multirow{2}{*}{$\begin{array}{l}\mathrm{p}- \\
\text { value }\end{array}$} & \multirow[t]{2}{*}{ AOR } & \multicolumn{3}{|l|}{$95 \% \mathrm{Cl}$} \\
\hline & & Lower & Upper & & & Lower & Upper & $\begin{array}{l}\text { p- } \\
\text { value }\end{array}$ \\
\hline Para one & 1 & & & & & & & \\
\hline Para 2-4 & 1.101 & 0.96 & 1.262 & $<.001$ & 1.19 & 1.003 & 1.412 & 0.046 \\
\hline Para 5+ & 0.77 & 0.667 & 0.887 & $<0.001$ & 0.958 & 0.775 & 1.185 & 0.694 \\
\hline \multicolumn{9}{|l|}{ Mainland/Zanzibar } \\
\hline Mainland urban & 1 & & & & 1 & & & \\
\hline Mainland rural & 0.241 & 0.206 & 0.282 & $<.001$ & 0.459 & 0.168 & 1.25 & 0.128 \\
\hline $\begin{array}{l}\text { Unguja (Zanzibar } \\
\text { Island) }\end{array}$ & 4.588 & 2.841 & 7.409 & $\begin{array}{l}< \\
0.001\end{array}$ & 3.934 & 1.568 & 9.871 & 0.004 \\
\hline Pemba (Pemba Island) & 3.693 & 2.123 & 6.423 & $\begin{array}{l}< \\
0.001\end{array}$ & 5.308 & 1.808 & 15.58 & 0.002 \\
\hline List of figures & & & & & & & & \\
\hline
\end{tabular}

INSERT Table 3 HERE

\section{Discussion}

This study used data from the 2015-16 Tanzania HIV and Malaria Indicators Survey to define factors associated with blood pressure check-ups among pregnant women reproductive age.

The study found that ANC booking increased the likelihood of blood pressure checkups among pregnant women. This agrees with findings reported by other studies conducted elsewhere in SSA countries [1214]. Blood pressure checkup is important for timely detection and management of hypertensive disorders of pregnancy $[5,6]$.

This study also found that age of women determined the blood pressure checkups during pregnancy. For example, in this study, women aged 34 + years were more likely to have adequate BP checkups than their colleagues. One study conducted in Rwanda supports this [19]. However, Ali et al., [2018] in their literature review study, found mixed findings arguing that the younger woman, had higher likelihood to utilize ANC services hence, increased the chance of blood pressure checkups. Besides, the same study showed that many studies supported older women i.e. aged between 25 to 30yrs or above had higher chance to check their blood pressure more frequently regarding to their frequent ANC service utilization. Sociocultural, ethnicity and geographical differences could be the cause for observed the differences. 
Other significant findings were place of residence, education level and wealth index of the woman. Two studies conducted in Ethiopia supports this argument [20,21]. Rural women lack exposure to health information concerning the importance of ANC service utilization. Also, rural women are less likely to be empowered than do urban women. Another significant finding in this study was that, pregnant women residing in Tanzania Mainland had a small chance get their BP checked during pregnancy compared to those dwelling in the Tanzania Zanzibar. However, the WCBA from Pemba were more likely to use ANC services for BP checkups than those from Unguja. Geographical differences and quality of health care services provided could be the reason.

According to this study, women with higher education were nine or more times likely to check their blood pressure during pregnancy. This was supported by a literature review study conducted elsewhere in African countries [21]. Educated women tend to have a greater awareness of the existence of ANC services and the benefits of using such services [22]. However, in contrast, Rurangirwa et al., [19] in their study found no any statistical significance.

The analysis also revealed that richer women were 2.3 times likely to get their blood pressure checked during pregnancy compared to their counterparts. This finding is supported by one study conducted in Indonesia. The researcher argued that richer women were four times more likely to be checked their BP during pregnancy compared to the poorer women [22]. Furthermore, although Okedo-Alex et al., [23] supported it, Rurangirwa et al., [19] argued against it. According to Rurangirwa et al, [19] having household assets (which were proxy to socioeconomic status) contributed nothing to the woman's reinforcement to utilizing ANC clinics for BP check-ups and other related services. This could be due to women empowerment differences, irrespective of the family wealth.

According to this study, the higher the parity, the reduced is the chance of the woman to get her blood pressure checked during pregnancy. This is attributed by the facts that high parity women tend to rely on their experiences from previous pregnancies and thus not feeling the need for ANC services [23]. The finding is further supported by two studies conducted elsewhere in China and Tanzania [24, 25].

\section{Conclusion}

Blood pressure checkups during pregnancy offer the opportunity for early detection timely management of HDP. The study revealed that rural dwelling pregnant women had a higher chance not to get their BP checked during pregnancy. It was also revealed that maternal age, education level, place of residence, wealth index and timing of ANC services significantly associated with blood pressure check-ups. The study identifies the need to explore significant factors associated with utilization of the available free reproductive health services across all public health facilities and to address prioritized intensive awareness programs and behavioral change interventions on the significance of BP checkups among pregnant women of reproductive age.

\section{Abbreviations}




\begin{tabular}{|ll|}
\hline ANC & Antenatal Clinic \\
\hline BP & Blood Pressure \\
\hline DHS & Demographic Health Survey \\
DBP & Diastolic Blood Pressure \\
HDP & Hypertensive Disorder of Pregnancy \\
\hline SBP & Systolic Blood Pressure \\
\hline TDHS-MIS & Tanzania HIV Demographic and Health Survey and Malaria Indicators Survey \\
\hline WHO & World Health Organization \\
\hline
\end{tabular}

\section{Declarations}

\section{Ethics approval and consent to participate}

Data collection and the survey content and protocol were approved by Tanzania's National Institute for Medical Research (NIMR), the Zanzibar Medical Ethics and Research Committee (ZAMREC), the Institutional Review Board of ICF International, and the Centers for Disease Control and Prevention in Atlanta, USA. Participants provided verbal consents and the household interviews took place privately. For participants under the age of 18 , written consent was requested from their parent or guardian.

\section{Consent for publication}

Not applicable

\section{Availability of data and material}

The data that support this analysis are available from the 2015-16 Tanzania HIV and Malaria Indicators Survey (THMIS). This survey was conducted by the National Bureau of Statistics (NBS) in collaboration with the Tanzania Commission for AIDS (TACAIDS) and the Zanzibar AIDS Commission (ZAC), the Ministry of Health, Community Development, Gender, Elderly and Children (MoHCDEC) (Tanzania) and the USAID-Funded Measure DHS project. Data is available from the authors upon reasonable request and with permission from MEASURE DHS

\section{Competing interests}

Authors declare there is no competing interest

\section{Funding}

The study was not funded 


\section{Acknowledgments}

The authors are grateful to MEASURE DHS for providing them with the data set.

\section{Authors' contributions}

FVM did the conceptualization, data analysis and drafted the manuscript and led the process of critical revision of the manuscript. MT wrote the introduction and discussion section and critical review of the manuscript. All authors read and consent for the manuscript to be submitted for peer review.

\section{Availability of data and materials}

Data set is available and can be shared on request

\section{References}

1. WHO. Monitoring Health for the SDGs [Internet]. Vol. 8, Ayan. 2019. Available from: https://apps.who.int/iris/bitstream/handle/10665/324835/9789241565707-eng.pdf.

2. UNICEF. Trends in estimates of maternal mortality ratio (maternal deaths per 100,000 live births) 2000-2017. 2019.

3. National Bureau of Statistics. Tanzania Demographic and Health Survey and Malaria Indicator Survey (TDHS-MIS) 2015-16. 2016. p. 172-3.

4. WHO. Maternal mortality Evidence brief. Matern Mortal [Internet]. 2019;(1):1-4. Available from: https://apps.who.int/iris/bitstream/handle/10665/329886/WHO-RHR-19.20-eng.pdf?ua=1.

5. Tessema GA, Tekeste A, Ayele TA. Preeclampsia and associated factors among pregnant women attending antenatal care in Dessie referral hospital, Northeast Ethiopia : a hospital-based study. BMC Pregnancy Childbirth. 2015;15:73.

6. Hinkosa L, Tamene A, Gebeyehu N. Risk factors associated with hypertensive disorders in pregnancy in Nekemte referral hospital, from July 2015 to June 2017, Ethiopia : case-control study. BMC Pregnancy Childbirth. 2020;20:16.

7. Osungbade KO, Ige OK. Public health perspectives of preeclampsia in developing countries: implication for health system strengthening. J Pregnancy. 2011;2011:481095.

8. Keskinkılıç B, Engin-Üstün Y, Sanisoğlu S, Şahin Uygur D, Keskin HL, Karaahmetoğlu S, et al. Maternal mortality due to hypertensive disorders in pregnancy, childbirth, and the puerperium between 2012 and 2015 in Turkey: A nation-based study. J Turkish Ger Gynecol Assoc. 2017;18(1):20-5.

9. World Health Organization. Trends in maternal mortality: 1990 to 2013 Estimates by WHO. UNICEF, UNFPA. The World Bank and the United Nations Population Division. Geneva; 2014.

10. Ministry of Health Community Development Gender Elderly and Children. Maternal deaths and their causes for January to December 2018. Dodoma; 2018. 
11. Nathan HL, Duhig K, Hezelgrave NL, Chappell LC, Shennan AH. Blood pressure measurement in pregnancy. R Coll Obstet Gynaecol. 2015;17:91-8.

12. Mgata S, Maluka SO. Factors for late initiation of antenatal care in Dar es Salaam, Tanzania: A qualitative study. BMC Pregnancy Childbirth. 2019;19(1):415.

13. Ebonwu J, Mumbauer A, Uys M, Wainberg ML, Medina-Marino A. Determinants of late antenatal care presentation in rural and peri-urban communities in South Africa: A cross-sectional study. PLoS One. 2018;13(3):1-16.

14. Gulema H, Berhane $\mathrm{Y}$. Timing of first antenatal care visit and its associated factors among pregnant women attending Public health facilities in Addis Ababa, Ethiopia. Ethiop J Health Sci. 2017;27(2):139-46.

15. World Health Organization (WHO). WHO Recommendations on Antenatal Care for a Positive Pregnancy Experience: Summary. World Heal Organ [Internet]. 2018;10(January):1-10. Available from: http://apps.who.int/iris/bitstream/handle/10665/259946/WHO-RHR-18.01eng.pdf;jsessionid=A4152E9CECB885109A6D3AC066FC63A3? sequence=1\%0Ahttp://apps. who.int/iris/bitstream/10665/259946/1/WHO-RHR-18.01-eng.pdf.

16. Alemu Y, Aragaw A. Early initiations of first antenatal care visit and associated factor among mothers who gave birth in the last six months preceding birth in Bahir Dar Zuria Woreda North West Ethiopia. Reprod Health. 2018;15(1):1-8.

17. Ministry of Health Ministry of Health. Development C, Gender, Elderly and Children (MoHCDGEC) [Tanzania Mainland], Ministry of Health (MoH) [Zanzibar], National Bureau of Statistics (NBS), Office of the Chief Government Statistician (OCGS) and I. Tanzania Demographic and Health Survey and Malaria Indicator Survey 2015-2016 [Internet]. Tanzania Demographic and Health Survey and Malaria Indicator Survey (TDHS-MIS) 2015-16. Dar es Salaam, Tanzania, and Rockville, Maryland, USA; 2016. Available from: https://www.dhsprogram.com/pubs/pdf/FR321/FR321.pdf.

18. Ali SA, Dero AA, Ali SA, Ali GB. Factors affecting the utilization of antenatal care among pregnant women: A literature review. Utilization of. 2018;2(2):41-5.

19. Rurangirwa AA, Mogren I, Nyirazinyoye L, Ntaganira J, Krantz G. Determinants of poor utilization of antenatal care services among recently delivered women in Rwanda; a population based study. BMC Pregnancy Childbirth. 2017;17(1):1-10.

20. Tiruaynet K, Muchie KF. Determinants of utilization of antenatal care services in Benishangul Gumuz Region, Western Ethiopia : a study based on demographic and health survey. BMC Pregnancy Childbirth. 2019;19:115.

21. $10.1371 /$ journal.pone.0214848 Id TT, Chojenta C, Smith R, Loxton D. Factors affecting utilization of antenatal care in Ethiopia: A systematic review and meta- analysis. 2019;1-24. Available from: http://dx.doi.org/10.1371/journal.pone.0214848. 
22. Efendi F, Chen CM, Kurniati A, Berliana SM. Determinants of utilization of antenatal care services among adolescent girls and young women in Indonesia. Women Heal. 2017;57(5):614-29.

23. Okedo-Alex IN, Akamike IC, Ezeanosike OB, Uneke CJ. Determinants of antenatal care utilisation in sub-Saharan Africa: A systematic review. BMJ Open. 2019;9(10):e031890.

24. Gross K, Alba S, Glass TR, Schellenberg JA, Obrist B. Timing of antenatal care for adolescent and adult pregnant women in south-eastern Tanzania. 2012.

25. Zhao Q, Huang ZJ, Yang S, Pan J, Smith B, Xu B. The utilization of antenatal care among rural-tourban migrant women in Shanghai: A hospital-based cross-sectional study. BMC Public Health. 2012;12(1):1012.

\section{Figures}

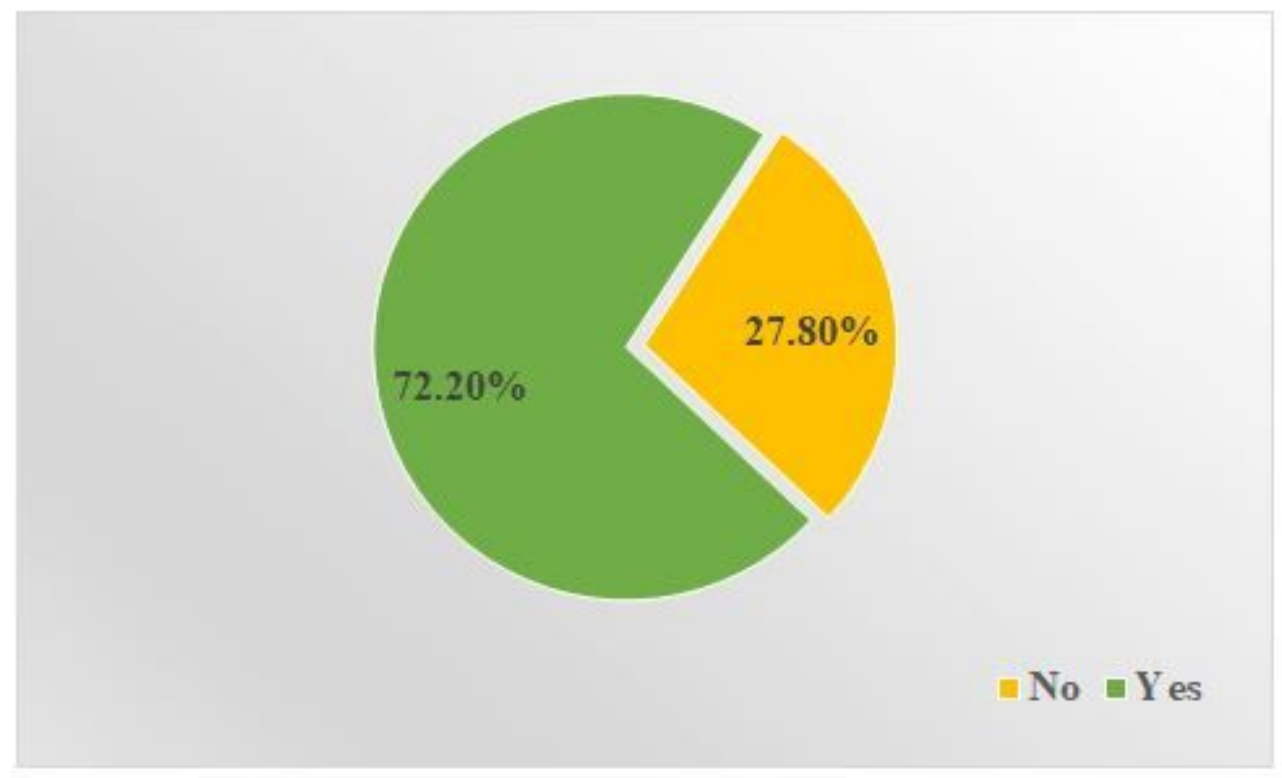

\section{Figure 1}

During pregnancy, blood pressure ever taken

\section{Supplementary Files}

This is a list of supplementary files associated with this preprint. Click to download.

- TDHSMIS201516.pdf 